\title{
Robust growth or anemic recovery in the U.S. and the global economy
}

\author{
Joseph E. Stiglitz * \\ Department of Economics, International Affairs Building, Columbia University, \\ 116th Street, New York, NY 10027, USA
}

Available online 1 August 2010

Keywords: Growth; Recovery; Global economy

\section{Introduction}

It is a real pleasure to be here to share some of my views. I am going to focus my remarks mostly on the short- to medium-term and on the demand side. Most of this panel has demonstrated why economics is often referred to as the "dismal science" - and this crisis has given us every right to be dismal. In the competition among the panel, I am going to try to out-distance the other panelists and be a little more dismal than they are about the short- to medium-term. I want to begin by putting the problem in context by thinking about the world as it was before the crisis. What sustained the American economy and, to a large extent, the global economy was America's housing bubble (and bubbles in a number of other countries), and that housing bubble allowed a consumption boom. As already mentioned by several speakers, this is what kept the U.S. economy going. It fueled high levels of consumption and a household savings rate that was close to zero. It was clear to almost everyone that this was not sustainable, which has been said many times in this session. Herb Stein once said, "That which is not sustainable will not be sustained." And it was not. As we officially emerge from the recession - the NBER has not confirmed it yet, but there has certainly been growth - the question really is, what will replace the sources of demand that existed prior to the crisis?

I think that there will be a real shortage of national as well as global aggregate demand. It will probably take a number of years to solve the problem. The long-term prognosis

\footnotetext{
* Tel.: +1 212854 0334; fax: +1 212 662-8474.

E-mail addresses: jestiglitz@gmail.com, Jb2632@columbia.edu.
} 
is that we are setting ourselves up for another crisis before we fully recover if we do not do something about the regulatory framework (that I outline more fully in my book Freefall).

\section{Slow recovery and the legacy of debt}

This is the first time that real incomes have not recovered to the levels where they were before a crisis; we now have a potential of going into the next crisis, whenever it might be, before we fully recover from the current one. Every crisis obviously leaves a legacy; one of the legacies that we are dealing with now is the legacy of debt, which affects both the public and the private sector, both households and firms. In the past, there were a number of ways that countries have dealt with an overhang of debt of the kind that American firms and households now face. The easiest way, of course, is inflation, but as that no longer has the approval of most parties, it is unlikely that we will inflate away the debt. Some foreign holders of dollars look at the U.S. economy and are afraid that we will go down that road. (Moreover, with so much of the debt being short-term, it is not so easy to inflate it away.)

Another way of dealing with an overhang of debt is restructuring. About one-quarter to onethird of all mortgages are "underwater," that is to say, the value of the mortgage exceeds the value of the house. Even if housing prices stabilized, they will not rise very rapidly, which means that these mortgages are likely to remain underwater for a very long time. The obvious solution is to try to restructure these mortgages. However, that has not really happened to any significant extent under the current administration's programs, which have combined small amounts of assistance with payments that are stretched out to allow individuals to stay in their homes; but the values of the mortgages have not been written down. Thus the number of mortgages remaining underwater has remained high, and the burden of the debt persists.

The third strategy, which is the one that the U.S. seems to be opting for, is called "prayer," where you hope or pray somehow to grow out of the problem. (It is also sometimes called muddling through.) Of course, it is not easy to grow out of debt if there is no growth, and the problem is that it is unlikely we will have robust growth anytime soon, especially if we do not deal with this issue.

\section{Inadequate U.S. aggregate demand}

Let me look more closely at each of the components of aggregate demand, to explain why I am somewhat pessimistic that we will return to robust growth anytime soon. Obviously the place to begin is consumption.

\subsection{The savings rate}

The savings rate has already increased substantially, and if we return to our historical average of around 7\% of GDP, there will be a big gap in aggregate demand arising from this source, relative to what we had before the crisis, which has to be filled. One of the important things to realize is that when you have had a shock of the kind that we have had, averages hide a lot of what goes on. Many of the people who have lost a lot are facing a number of constraints. Older people have lost a large fraction of their wealth in the form of home equity, since for most Americans their most important asset is their home; if their homes are underwater, that means they have negative home equity. 
There are many other people whose houses are not underwater but whose home equity has been wiped out. The implication is that the effect on average savings rates could very plausibly be markedly higher than one might otherwise have expected, because of wealth effects and the constraints that individuals face, such as the fact that when you retire, you have no other source of income. Those who are retired and face large losses in their wealth are forced to cut back; and those approaching retirement may substantially increase savings for retirement to make up for the shortfall. Many other individuals were living beyond their means by borrowing. For many of them, the borrowing constraints will become tighter, and they will be forced to cut back on consumption.

The only saving grace is the fact that the U.S. has had increasing inequality, so that more and more of those at the top are unaffected by these problems. Still, on average, it would seem that we are going to receive a blessing in the long-run from the higher savings rates but a real problem in the short-run due to the resulting weakness in aggregate demand. I want to emphasize that the remarks I have just made say nothing about the banking system. It is not that people cannot borrow but that they do not want to borrow. The not fully functioning financial system leads to an additional constraint that will increase the savings rate: if we have better regulations on housing and restrict mortgages, that would also lead to higher savings. In some ways, some of the things we have been doing entail slowing down the adjustment, and that opens up the possibility of a more prolonged recovery.

When one thinks about savings, one immediately turns to the labor market and the uncertainties about job prospects. Most of what I want to say has already been covered, but there are a couple of points that I want to emphasize that have not been noted. The first is that the average hours worked per week are at a very low level, about $33 \mathrm{~h}$ per week for those who are working full-time. The average went up last month to 33.2, but that is still very low. This means that there will have to be a significant increase in the demand for labor before we get back to normal hours - and that may slow down the pace of hiring.

\subsection{The weak recovery}

The second observation is that, while employment always lags recovery, the real question is the strength of the recovery itself. Unless economic growth is large enough to offset the natural increase in the labor force and the growth in productivity, then, even without adjustment, there is no reason for employment to start growing. There is considerable debate about future productivity growth, but if it continues at the rate of the late nineties and early years of this decade, then growth has to be somewhere between $2.5 \%$ and $3.5 \%$ to be strong enough to create jobs for the new entrants into the labor force. However, most of the forecasts of GDP growth for the next year or two do not have us growing significantly faster than the lower bound of these numbers. So, growth itself, in the way that it is forecast over the next 2 years, is not expected to be large enough to provide jobs for the new entrants in the labor force and to reduce significantly the "jobs deficit" that has opened up over the last 2 years. The only thing that could really save us - that is, enable the unemployment rate to go down significantly - is to have the good fortune of productivity stagnation; some people are praying for that.

\subsection{Productivity stagnation}

Several people on this panel are suggesting that productivity stagnation may actually come about. But, considering that median income in 2008 in the United States was lower than it was 
in 1999, it is not good news for workers, to tell them that the way we will bring down the unemployment rate is in fact to have a productivity slowdown; this will cause stagnant wages as far as the eye can see. Nor is it a good message for a robust return to growth for the American economy: if most Americans realize that they face this kind of wage stagnation, there is no reason to believe that they will start consuming as they did in the past.

There is one further aspect of what may contribute to the slowdown in productivity that has not been talked about. One of the hallmarks of America's labor market is a high level of mobility: when a job opportunity comes up, they will move from one place to another. But America has an owner-occupied housing structure, and in many parts of the country it is very hard to get rental housing. To move from one place to another, you have to sell your home and buy another one. If you have negative equity, however, when you sell your home you have no money for the next down payment, unless, of course, we go to the obvious solution of not requiring one. But that is the kind of mortgage market that got us into trouble. In short, unless we return to the no or low down payment loans that contributed so much to creating the current crisis, mobility in the American labor market may be very constrained. This will almost inevitably have an adverse effect on our productivity.

\subsection{Financial sector problems}

There have already been a number of mentions of the other problems facing the U.S. economy, for instance in the financial sector. The number of foreclosures that are expected in 2010 is actually larger than occurred in 2008 and 2009, so one of the consequences of not having dealt with the problems of underwater mortgages is that these foreclosures are mounting.

Furthermore, if we look at investment, one of the real sources of problems is the small- and medium-sized enterprises. At present, large enterprises do have access to capital, but the smalland medium-sized enterprises do not. And the data which I have seen suggest that the problems for small- and medium-sized enterprises are becoming worse. One of the reasons is that they depend very heavily on asset-backed loans, and when the property values go down, their access to loans decreases. The credit lines they relied upon are expiring, and as they expire, they are not being renewed. This is part of the dynamics of adjustment to the problems which began in 2007 and which affected the U.S. in 2008 and the rest of the world in 2009. We are working through the dynamics in a very slow and serious way.

One thing that has not been emphasized enough in this panel discussion is the risk of the exit from quantitative easing, relying on the Federal Reserve buying up all of the mortgages. The Fed has committed itself to leaving this stance in March 2010. Now, if it does that, it goes from a position of being the buyer of almost all the mortgages to not buying them. If it stops buying the mortgages, mortgage interest rates will rise, and the mortgage markets will be very adversely affected. It is going to be very difficult to have a smooth exit from the situation where the Fed has become virtually the entire mortgage market.

\section{Inadequate world aggregate demand}

Until this point, I have focused on the shortfall in U.S. aggregate demand. In a world of globalization, what matters is global aggregate demand. This raises the question: why is it that countries around the world are saving so much? The reason obviously is that their experience, which has been reinforced by this crisis, is that those countries with large amounts of reserves have fared better when they confront a crisis. The leaders of many countries that went through the 
1997-1998 East Asia crisis have said, "never again" - never again will we allow the loss of our sovereignty and the imposition of policies that converted downturns into recessions, recessions into depressions, policies that are the opposite of those that the U.S. has adopted.

So, while it is good news that there is increasing recognition of the problem - that inadequate international frameworks for dealing with crises have led to "self-insurance" through large buildups of reserves (a form of precautionary savings) - it will take time to create new frameworks in which governments have sufficient reserves over the long-run that they can dispense with these reserves. While they may have confidence in the current individuals who are running the institutions, they do not have confidence over the long-run, and building up reserves is a matter of the long-run.

This is one of the reasons why I have argued that one of the things that should be done to restore robust and stable growth is to reform the global reserve system. This idea was very central to Keynes' view of how to maintain strong global aggregate demand, and I have described in some of my own work (Making Globalization Work) how one can create this global reserve system. The UN Commission of Experts on Reforms of the International Monetary and Financial System emphasized the importance of this reform in its report last September.

I think that this is absolutely essential if we are going to induce a reduction in the level of savings in the developing world. But it is wrong to focus only on the savings glut: one ought to look at it more symmetrically, as it is really a dearth of investment. When I look at the world, I see the problems of global warming and of global poverty, and it seems to me that addressing them provides large investment opportunities. Studies of investments in these and many other areas suggest that they yield high (social) returns. In some cases, there is a discrepancy between social and private returns, e.g. because of the failure to price carbon emissions.

But there is a further problem: the financial market's ability to transfer the funds from those who are doing the savings to where the needs are. A real opportunity was missed at the Copenhagen Climate Conference. A carbon price that reflected the real social scarcity, at something like $\$ 80$ a ton, would provide strong incentives for these investments and would provide the global aggregate demand to fill the hole that I described earlier. These are the directions in which we should be going in order to help restore the global economy to robust growth. 